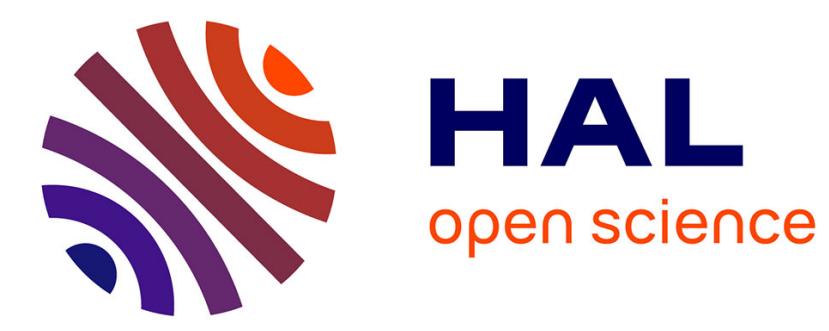

\title{
3D printing for rapid sand casting-A review
}

Meet Upadhyay, Tharmalingam Sivarupan, Mohamed El Mansori

\section{To cite this version:}

Meet Upadhyay, Tharmalingam Sivarupan, Mohamed El Mansori. 3D printing for rapid sand castingA review. Journal of Manufacturing Processes, 2017, 29, pp.211-220. 10.1016/j.jmapro.2017.07.017 . hal-02417595

\section{HAL Id: hal-02417595 \\ https://hal.science/hal-02417595}

Submitted on 18 Dec 2019

HAL is a multi-disciplinary open access archive for the deposit and dissemination of scientific research documents, whether they are published or not. The documents may come from teaching and research institutions in France or abroad, or from public or private research centers.
L'archive ouverte pluridisciplinaire HAL, est destinée au dépôt et à la diffusion de documents scientifiques de niveau recherche, publiés ou non, émanant des établissements d'enseignement et de recherche français ou étrangers, des laboratoires publics ou privés. 


\title{
3D printing for rapid sand casting-A review
}

\author{
Meet Upadhyay ${ }^{\mathrm{a}, \mathrm{b}}$, Tharmalingam Sivarupan ${ }^{\mathrm{a}, *}$, Mohamed El Mansori ${ }^{\mathrm{a}}$ \\ a MSMP-EA7351, Arts et Métiers ParisTech, 2 Cours des Arts et Métiers, 13617 Aix-en-Provence, France \\ ${ }^{\mathrm{b}}$ National Institute of Technology, Srinivas Nagar, Surathkal, Mangalore, Karnataka 575025, India
}

Keywords:

Additive manufacturing

Sand casting

3D printing

Sand molds

Rapid prototyping

Rapid manufacturing

3D sand moulds

\section{A B S T R A C T}

There are many 3D printing technologies available, and each technology has its strength and weakness. The 3D printing of sand moulds, by binder jetting technology for rapid casting, plays a vital role in providing a better value for the more than 5000 years old casting industry by producing quality and economic sand moulds. The parts of the mould assembly can be manufactured by precisely controlling the process parameters and the gas producible materials within the printed mould. A functional mould can be manufactured with the required gas permeability, strength, and heat absorption characteristics, and hence the process ensures a high success rate of quality castings with an optimised design for weight reduction. It overcomes many of the limitations in traditional mould design with a very limited number of parts in the mould assembly. A variety of powders, of different particle size or shape, and bonding materials can be used to change the thermal and physical properties of the mould and hence provide possibilities for casting a broad range of alloys. Limited studies have been carried out to understand the relationship between the characteristics of the printed mould, the materials used, and the processing parameters for making the mould. These deficiencies need to be addressed to support the numerical simulation of a designed part, to optimise the success rate and for economic as well as environmental reasons. Commonly used binders in this process, e.g. furan resins, are carcinogenic or hazardous, and hence there is a vital need for developing new or improved bonding materials.

\section{Contents}

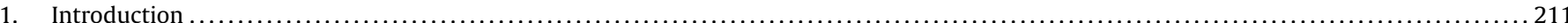

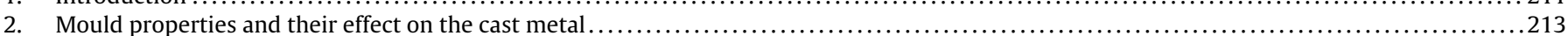

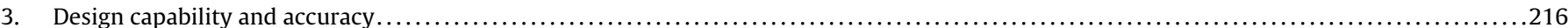

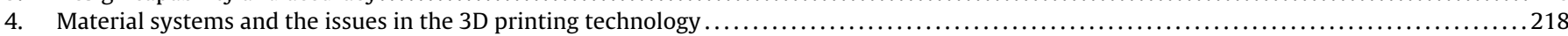

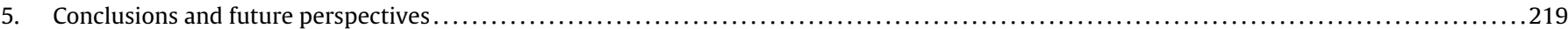

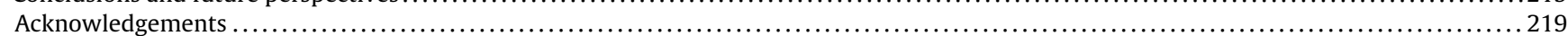

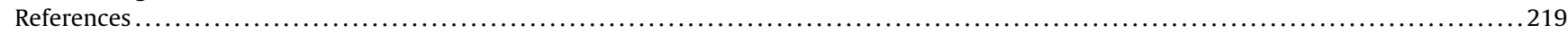

\section{Introduction}

A definition of additive manufacturing (AM) has been given as "process of joining materials to make parts from 3D model data, usually layer upon layer, as opposed to subtractive manufacturing and formative manufacturing methodologies" [1]. AM began as a method for design engineers to realise design concepts without heavily investing in the subsequent manufacturing processes. Advancements in

\footnotetext{
* Corresponding author.

E-mail addresses: tharmalingam.sivarupan@ensam.eu, ktsrupan@gmail.com (T. Sivarupan).
}

Rapid Prototyping (RP) enabled the conversion of parametric CAD (computer aided design) data to physical prototypes which could be tested to check if they met the design criteria. This saved not only time but also allowed the testing of multiple models [2]. Since then, its applications have expanded into the aerospace industry, medicine, architecture and more. This expansion has been aided by the wide-scale development and innovation in additive manufacturing processes. As the accuracy and the versatility of the processes improve, the focus of the industry is shifting from Rapid Prototyping to 'Rapid Manufacturing' i.e. the process of manufacturing complete parts from a rapid prototyping device [3,4]. Wohlers [4] states that machines must allow the production of finished parts and an improvement in materials for better penetration of rapid 
Table 1

The 3D printed sand mould for casting and their production method, properties, and applications.

\begin{tabular}{|c|c|c|c|c|c|c|}
\hline Ref. & Powder & Particle size & Suitable binder & $\begin{array}{l}\text { Properties } \\
\text { achieved (3PB) }\end{array}$ & Heat treatment & Application \\
\hline$[14,15]$ & Plaster-ceramic composite & & Zb56 & & $\begin{array}{l}464 \mathrm{~K}\left(190^{\circ} \mathrm{C}\right) \text { for } \\
4-8 \mathrm{~h}\end{array}$ & Casting non-ferrous metals \\
\hline [16] & Chromite & & Furan or phenol & & & \\
\hline [17-19] & Silica, & $140 / 190 / 250 \mu \mathrm{m}$ & Furan & $250-300 \mathrm{Ncm}^{-2}$ & $\begin{array}{l}\text { No heat treatment } \\
\text { required }\end{array}$ & Casting non-ferrous metals \\
\hline$[18,19]$ & Silica & $140 / 190 / 250 \mu \mathrm{m}$ & Phenolic (hot hardening) & $250-500 \mathrm{Ncm}^{-2}$ & & Casting ferrous metals \\
\hline [16] & Zircon & & Furan & & & \\
\hline [16] & Chromite & & & & & $\begin{array}{l}\text { Heavy duty grey iron and } \\
\text { steel }\end{array}$ \\
\hline [16] & Ceramic Beads & & Furan & & & $\begin{array}{l}\text { Including steel alloys } \\
\text { casting, sand cores }\end{array}$ \\
\hline
\end{tabular}

manufacturing in the new markets. This can be seen in the variety of processes that fall under the umbrella of rapid casting which use AM based technology to aid investment and sand casting processes [5]. These include Selective Laser Sintering, Laminated Object Manufacturing, Fused Deposition Modelling, Stereo lithography and especially, the 3D printing (3DP) process to produce sand cores, patterns, shells and entire mould assemblies for sand casting applications. The interest in rapid casting using AM has increased with the general increase in interest and industrial proliferation of AM, as can be seen in Table 1.

Recently, 3DP has gained prominence as a rapid casting process which is a cost-effective [5] and relatively fast method capable of working with a wide variety of materials and post treatment processes $[7,8]$. 3DP, based on the inkjet printing technology, was developed at Massachusetts Institute of Technology (MIT) [9-11] and licensed to six companies. Since then the process has been used for the production of ceramics, metal parts with copper infiltration and then polymer moulds for patterns in rapid casting. The process is similar to other powder-based processes and uses an inkjet printer head to spray the binder onto the job box (the build platform). The process begins with a fine layer of sand, pre-mixed with the activator, distributed on the job box surface by the recoater and followed by spraying binder in the selected area of the job-box plane, according to each slice (cross section) of the part to be printed. As the bonding reaction takes place, the sand par- ticles stick together only within the region where the binder was sprayed;the other region is covered by loose sand. The platform moves downward by a set distance (layer thickness), and the process repeats until all of the slices of the part are completely printed and a final sand layer is spread. Fig. 2 shows a schematic of the process. Recently, companies such as ExOne ${ }^{\mathrm{TM}}$, Voxeljet $^{\mathrm{TM}}$, and ZCorp $^{\mathrm{TM}}$ have expanded this system to produce sand moulds using binder jetting technology. Thus, while the process has been used for rapid tooling, its application in the field of manufacturing of sand moulds for direct casting is rather new and unexplored, Fig. 1(bthe green colour plot). However, this application is imperative, not limited to, for small volume production of complex parts as it offers significant advantages such as large reductions in the lead time for the design of moulds, easy integration of cores and gating system in the design of mold assembly, and production of parts with complex internal geometries. Amongst all the rapid tooling and manufacturing processes, this makes the most sense for quick integration into existing industries as it can produce high quality and complex sand moulds with the required properties for a better casting solution within a short time frame [12]. Furthermore, compared to the traditional sand mould making process, binder jetting can produce optimised part designs for weight reduction up to $33 \%$ without losing the engineering requirement of the component [13]. This has been possible due to the vast body of knowledge relating to sand casting and the evolution of cast parts .

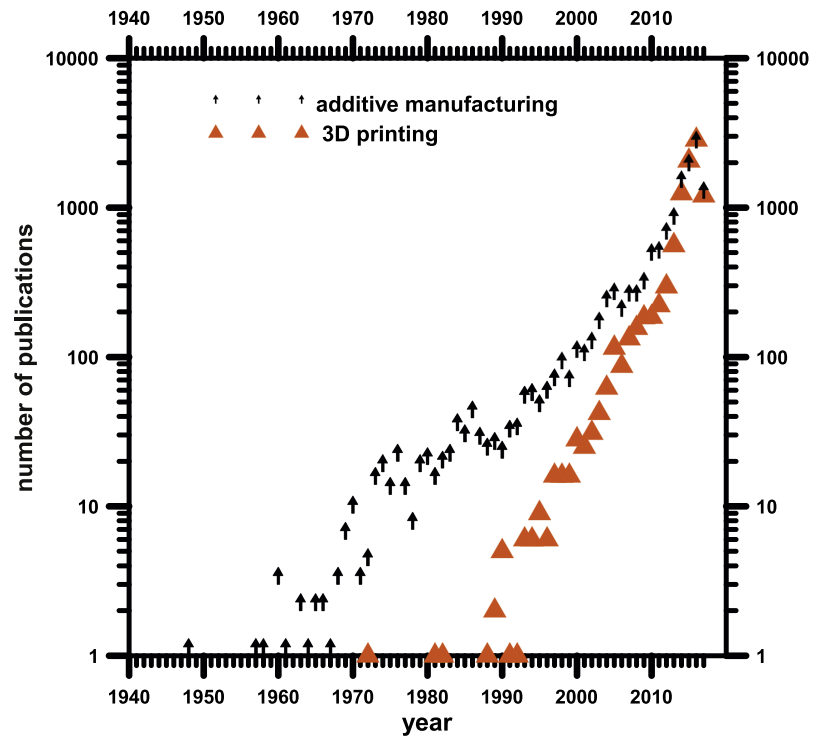

(a)

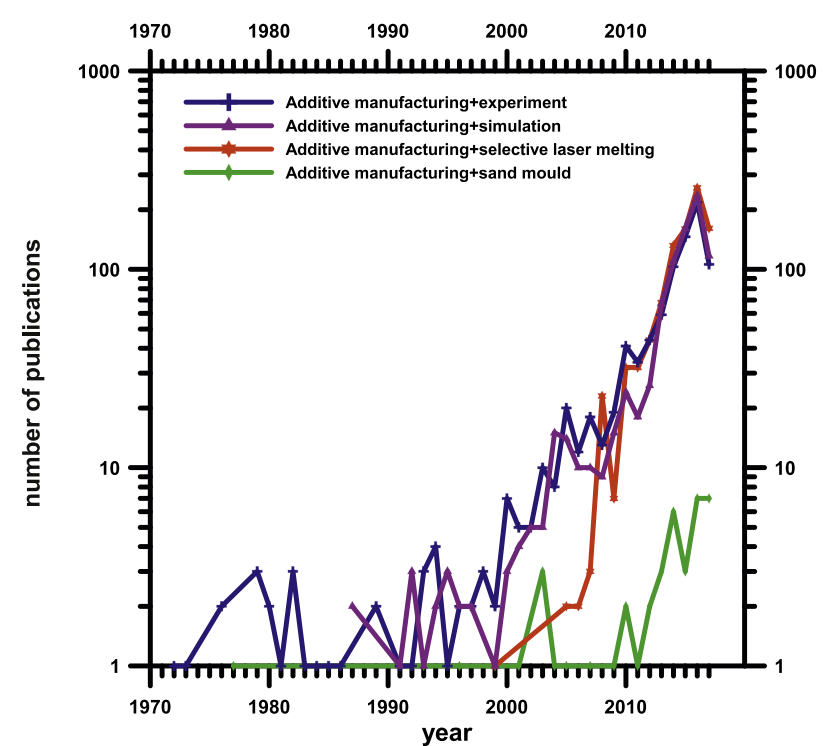

(b)

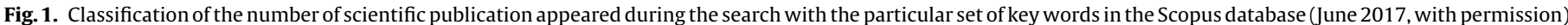

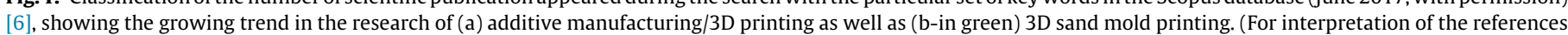
to colour in this figure legend, the reader is referred to the web version of this article.) 


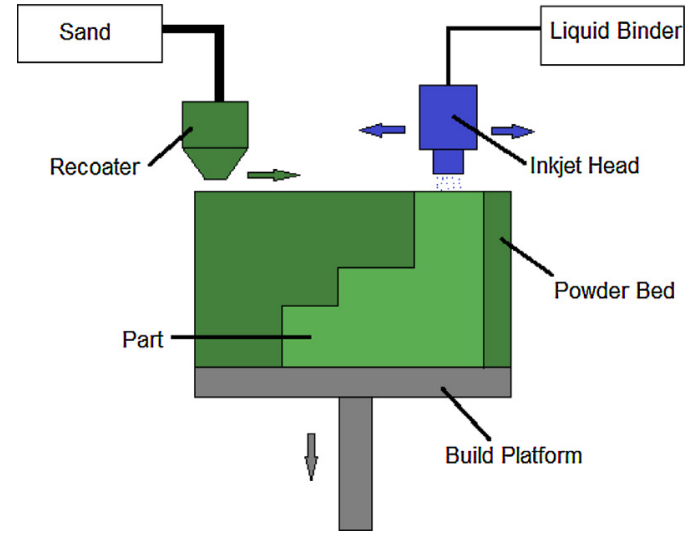

Fig. 2. A diagram of the binder jetting process, e.g. 3D sand mould printing. Acid mixed sand is spread by the recoater on the build platform and then the print head inkjets the binder according to each slice, cross-sectional area, of the part to be printed before it moves downwards and the process continues until the last slice is printed.

The existing open literature related to 3D sand mold printing has been classified in the following categories.

$\sqrt{ }$ Mould properties and its effect on the cast metal.

$\sqrt{ }$ Design accuracy and capability.

$\sqrt{ }$ Material Systems and the issues in the 3D printing technology.

Let's first discuss the production of sand moulds and their properties, and then the effect of the various types of the moulds on the casting outcome.

\section{Mould properties and their effect on the cast metal}

There are many types of sand, binder, and activator systems are being used to produce 3D printed sand moulds, for a variety of alloy casting applications with the required properties, Table 1 . Organic binders used for 3D printing can produce toxic gases during casting and hence are not environmentally friendly [20], even though they better serve the industry. Also, it is found that furan poses a health risk to the operators as it is a possible human carcinogen [21]. There is a vital need for alternative binders. A low gas emission silicate binder is available in the market especially for the 3D sand mould printing, and this needs to be studied further [22]. The properties of sand moulds produced by the 3D printers can be controlled by numerous factors during the printing and or curing cycle (for phenolic or ZCast ${ }^{\circledR}$ moulds). These properties are affected by the characteristics of the sand, the concentration and the type of binder and activator, printing speed (powder recoating speed) [17], job-box co-ordinate and build-orientation of the specimen printed $[17,23]$, and layer $[8,24]$ thickness. It has been found that decreasing the layer thickness and increasing the binder saturation improves the tensile strength but reduces the surface quality [24].

Research has also focussed on the effect of curing parameters on the mould properties. Ref. [14] investigated the effects of curing temperature and time on the mechanical properties such as strength and permeability of the sand moulds. These were produced using the ZCast 501 powder and Zb56 resin binder system.
The temperature was varied from $150^{\circ}$ to $250^{\circ} \mathrm{C}$ with a curing time variation of $4-8 \mathrm{~h}$ to characterise both the individual and combined effects of these parameters on the compressive strength and permeability of the printed mould. Using a statistical design of the experiment, a linear regression model with 99\% confidence level was achieved. It was concluded that permeability increased with the curing time, due to the loss of volatile components. However, prolonged heating could have caused fusion of low melting temperature phases and embrittlement of gypsum plaster leading to reduced permeability and compressive strength respectively. The optimum time and temperature are identified in Table 2. While the study omitted the other characteristics of the printed mould such as refractoriness, cohesiveness, and collapsibility, this research sparked the interest to develop knowledge for the efficient application of the process to manufacture quality castings.

Another study attempted to optimise the temperature and time for maximum compressive strength using cylindrical ZCast samples [25]. Compared to Ref. [14], however, the range of temperature was $423-523 \mathrm{~K}\left(150-250^{\circ} \mathrm{C}\right)$, and the compressive strength varied from $6.2-2.4 \mathrm{MPa}$. The study reported a negligible effect of curing time on the strength and optimised the temperature. These contradictory results call for more experimentation in this area.

Others have tried to optimise the curing cycle by considering the casting defects due to off-gassing of volatile binder components [26]. ZCast powder requires (8-9\%) higher amounts of binder compared to foundry sand (1.4\%) due to its high surface area to volume ratio of the particles. Various curing cycles were performed to properly eliminate the binder and the part cast into the resulting moulds. A curing cycle of $316^{\circ} \mathrm{C}$ for $1 \mathrm{~h}$ was found to be optimum with no visible defects and sufficient mould strength.

Subsequently, Ref [27]. compared the strength and binder burnout characteristics of the ExOne ${ }^{\mathrm{TM}}$ furan resin and sulphonic acid catalyst system (3D printed) with commercially available sand and binder systems (non-3D printed); to evaluate binder burnout, the samples were subjected to curing cycles of $378-1173 \mathrm{~K}\left(105^{\circ} \mathrm{C}\right.$ to $900^{\circ} \mathrm{C}$ ) and it was reported that the ExOne ${ }^{\mathrm{TM}}$ printed specimens had higher strength (1.3 MPa), Figs. 3 and 4, due to the wellcontrolled distribution of sand and binder. The printed specimens also maintained their shape up to a higher burnout temperature of $723 \mathrm{~K}\left(450^{\circ} \mathrm{C}\right)$. The 3D printed system even performed better than the traditionally prepared sand mould using furan resin and phenolic acid system in the aspects above. This study demonstrates that printed moulds are superior in quality to traditionally manufactured moulds and have lower and precisely controllable binder content which leads to minimised gas generation and hence improved castings. The ExOne ${ }^{\mathrm{TM}}$ company has also introduced a new cold hardening phenolic binder system with improved properties and environmental benefits, compared to the furan system [28]. The factors affecting the properties of a 3D printed specimen are schematically shown in Fig. 3.

Another important factor which influences the quality of the cast metal parts is the heat absorbed by the mould and the thermal gradient existing at the mould metal interface. The thermal properties and binder degradation characteristics of 3D printed (furan and phenolic systems) spherical cores using inverse Fourier Thermal Analysis have been reported in Ref. [29]. The parameters evaluated

Table 2

Optimum curing time and temperature required for the $\mathrm{Zcorp}{ }^{\mathrm{TM}} 3 \mathrm{D}$ printed mould, in addition to the printing time.

\begin{tabular}{|c|c|c|c|c|}
\hline Ref. & Property & Time (hours) & Temperature (K) & $\begin{array}{l}\text { Properties achieved under } \\
\text { various conditions }\end{array}$ \\
\hline$[14]$ & Compressive Strength of ZCast501 powder (MPa) & 5.5 & 446.14 & $\sim 0.5-1.2$ \\
\hline [14] & Permeability (milli Darcy) & 6.2 & 500.14 & 2200 \\
\hline [25] & Compressive Strength (MPa) & $4-6$ & 423 & $6-6.9$ \\
\hline [24] & Maximum Flexural stress (MPa)of ZP102 & & & $3.83-7.33$ \\
\hline$[24]$ & Maximum Tensile stress (MPa)of ZP102 & & & $1.99-3.562$ \\
\hline
\end{tabular}




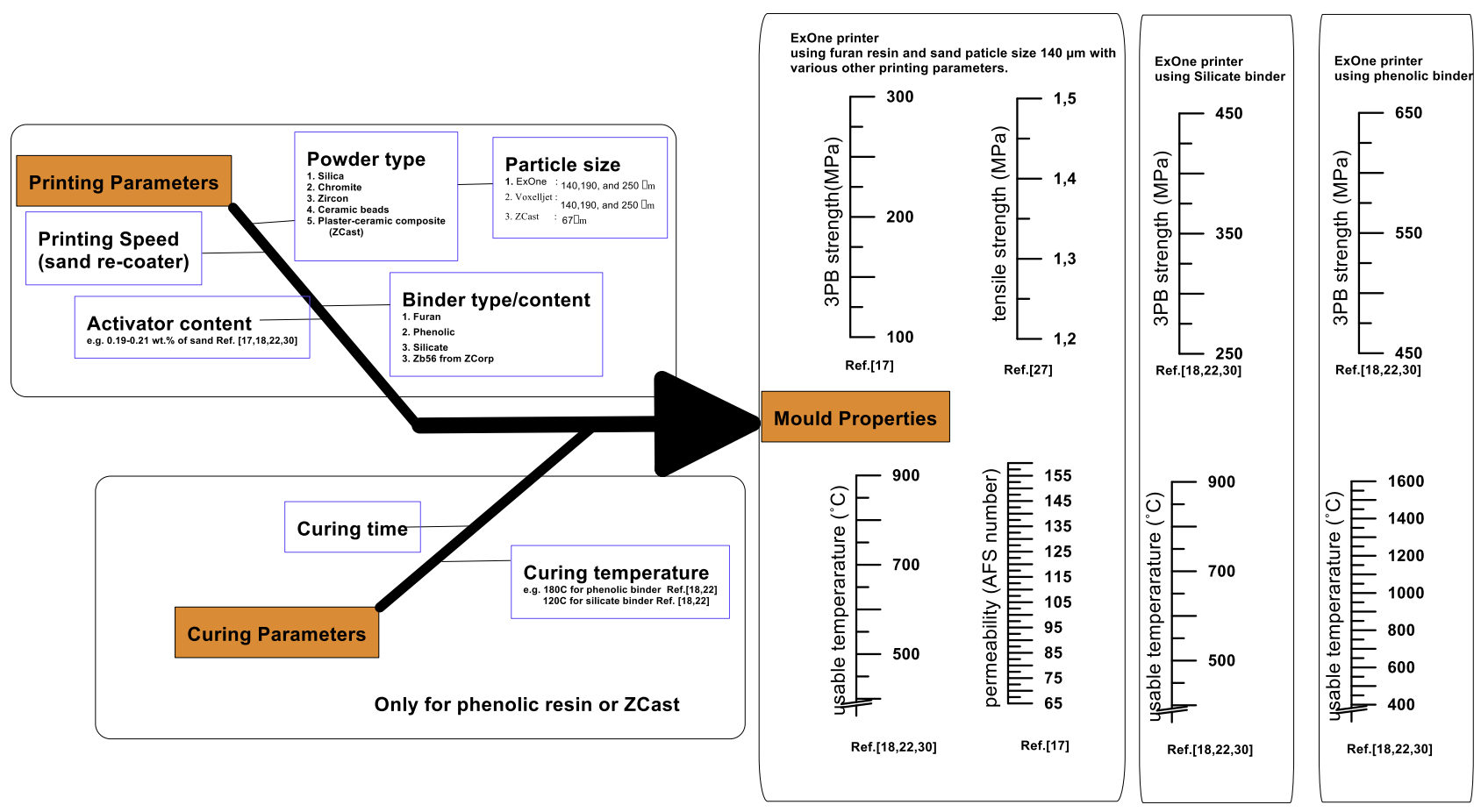

Fig. 3. Factors influencing mould properties and a set of experimentally obtained/advertised properties of the 3D printed mould [17,18,22,27,30].

were the total and the fraction of heat absorbed, and the rate of heat absorption under casting conditions of iron and aluminium. Furan absorbed $30 \%$ more heat $(283 \mathrm{~kJ} / \mathrm{kg}$ vs $221 \mathrm{~kJ} / \mathrm{kg}$ ) and had a higher rate of heat absorption, which was attributed to the difference in behaviour of the thermal degradation of the binder systems, and the presence of higher water content in the phenolic system. The furan system was found to perform better because of its better cooling capacity, smoother and moderate degradation. This data will be important to develop numerical simulations of the binder degradation and heat distribution. The study is different in the way that it considers the characteristics of the core which will help in the better design of cores and study their effects on the internal features of the cast part.

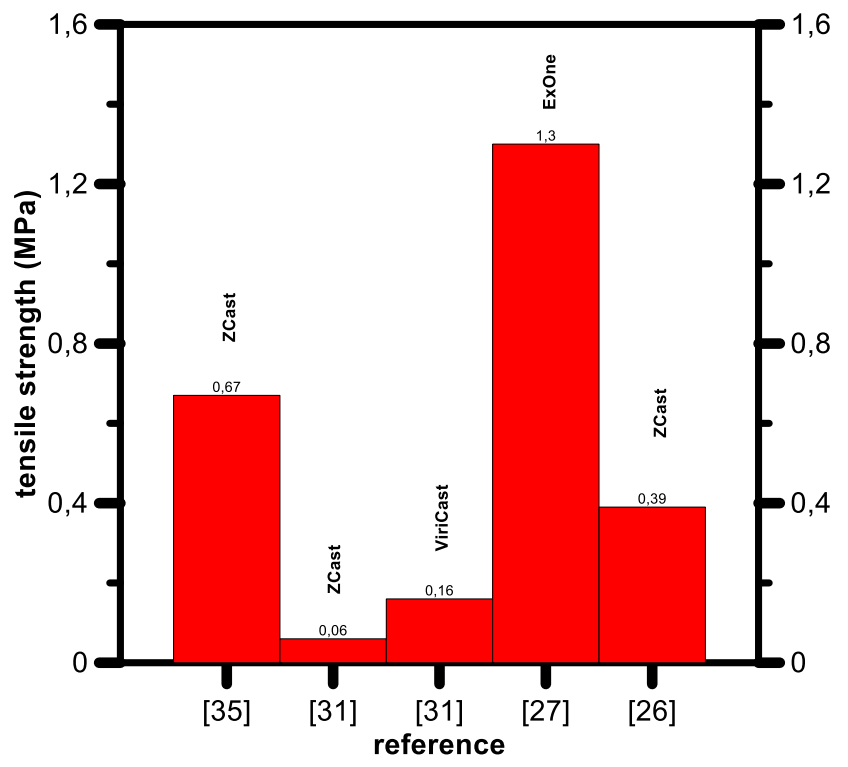

The dependence of the phenol-formaldehyde bonded mould properties on the bed position, build orientation and density was studied in Ref [23]. The dimensional accuracy, tensile strength, compressive strength and rigidity at elevated temperatures were measured. The researchers observed that the distribution of the sand by the spreader/recoater influences the uniformity of the sand deposited which in turn affects the various properties. The process, however, showed good consistency over the 20 day test period. Parts obtained were of a slightly larger size due to the binder bleed. The yield stress in the tensile test, the minimum crush stress and the impact strength was found to be $1.75 \mathrm{MPa}, 5.86 \mathrm{MPa}$ and $1.74 \mathrm{kPa}$ respectively. The samples debonded partially at the temperature of $450^{\circ} \mathrm{C}$ and completely at $850^{\circ} \mathrm{C}$. These properties can be used by

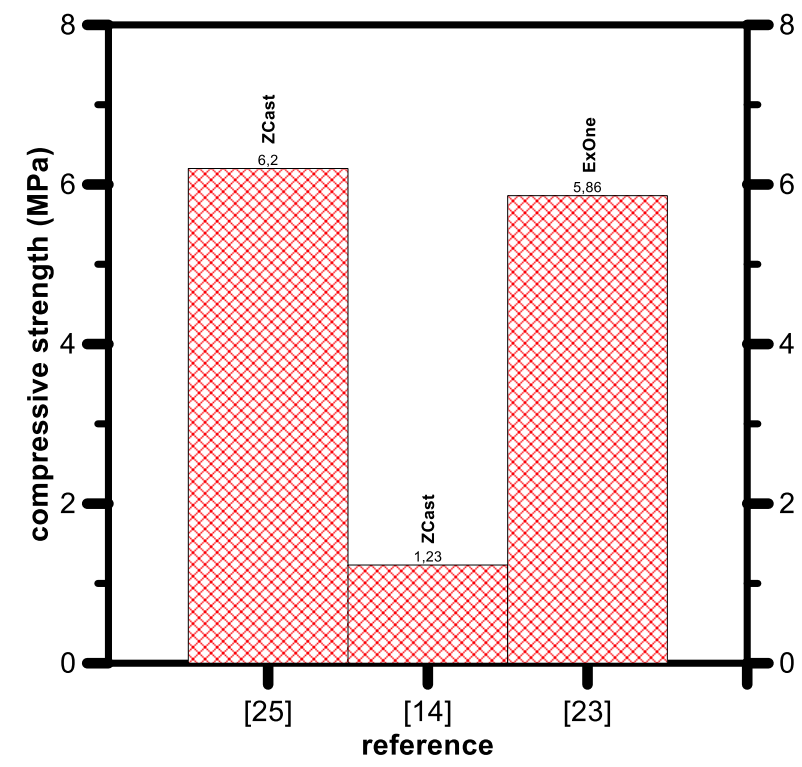

Fig. 4. Comparison of tensile strength and compressive strengths obtained on the 3D printed specimens of sand, in the open literature [14,23,25-27,31,35]. 
Table 3

Surface roughness values obtained and average prediction error for various cast alloys [36].

\begin{tabular}{lll}
\hline Metal & Surface Roughness $(\mu \mathrm{m})$ & Average Prediction Error $(\%)$ \\
\hline Aluminium & $6.46-7.11$ & 10.6 \\
Brass & $10.91-11.76$ & 2.43 \\
Copper & $10.72-12.08$ & 3.12 \\
\hline
\end{tabular}

designers to understand the capabilities of the process by appreciating the flexibility offered while providing properties comparable to traditional processes.

Apart from the properties of the mould, it is also important to study the effects of the mould on the produced castings. As stated before, these can be due to the heat transfer characteristics at the mould - metal interface and also due to the off gassing during the binder degradation process. The heat transfer characteristics affect the solidification rate and consequently the strength and density of the cast part. The evolution of volatile components leads to undesirable surface irregularities.

A study in [31] compared two 3DP powders; ViriCast ${ }^{\mathrm{TM}}$ and ZCast to no bake foundry sand, based on their handleability and the properties of the cast metal produced. Cylindrical specimens of $25.4 \mathrm{~mm}$ diameter and $101.6 \mathrm{~mm}$ long were cast out of A356 alloy and tested for surface roughness, density, hardness, porosity, and microstructure. The hardness and strength of the parts cast from the 3D printed moulds were comparable to traditionally cast A356 alloy. However, it was mentioned that the heat treatment conditions of the no bake and 3DP casts were different, and hence their hardness and strength cannot be compared. While the no bake sand had higher handleability and density of cast parts (marginally), the porosity was much lower. On the other hand, the ZCast moulds had a much greater surface roughness. It was concluded that the powders used for the 3D printing were suitable to produce the cast parts with similar characteristics as that of no bake sands.

The effect of volume of casting, pouring temperature and the shell mould wall thickness on the surface roughness of produced castings was identified in Ref. [32]. Mould of different volumes and shell thicknesses were printed and used to cast aluminium, copper and brass. The surface roughness was found highly dependent on the pouring temperature ( $97.55 \%$ contribution) and then, on the shell wall thickness ( $2 \%$ contribution). This may be attributed to the decomposition of volatile substances at the mould-metal interface, and hence the gas produced may have influenced the surface roughness of the cast part beyond the effect of the sand particle size. There was no significant effect due to the volume of the design. Another study tested parts made out of split pattern shells made by 3D printing [33]. These parts were compared to those produced by moulds fabricated by investment casting. The moulds with decreasing shell thickness were printed to evaluate the effect of the thickness on the casting, $3 \mathrm{~mm}$ and $6 \mathrm{~mm}$ were the optimum values found for ZA12 zinc alloy and A356 aluminium alloy. Compared to investment casting, the $3 \mathrm{D}$ printed parts performed slightly worse regarding surface roughness and hardness. This is due to the microstructure which is influenced by the solidification which in turn depends on the ability of the mould to transfer the heat [34]. Another point of view would be that a higher amount and/or non-uniform distribution of the binder around the sand particles within the 3D printed mould; the binder sprayed by the print head may not wet the whole surface of each sand particles and the distribution depends on the viscosity of the binder and the speed of the chemical reaction. An important conclusion to be drawn is that there is no 'one size fits all' approach which can be taken to optimising process parameters. It depends on the size and shape of the part to be cast.

The mechanical and thermal properties of the moulds produced using the ZCast mixture by the ZPrinter 310 Plus have been characterised in [35]. These properties were then used to optimise the mould wall thickness and to model the casting process. The tensile strength of the parts has been measured by varying their thickness and calcination duration. A thickness of $7 \mathrm{~mm}$ after calcination was found to be stronger than the manufacturer specified thickness, of $15 \mathrm{~mm}$, allowing better economy in mould printing. The heat transfer characteristics such as thermal diffusivity, heat capacity, and thermal conductivity were determined and used to draw the cooling curves of AK81. These have shown good convergence with experimental cooling curves. This study has bridged the knowledge gap regarding mould properties and is essential for process modelling. However, more mould properties such as permeability, density, and their correlation with thermal properties need to be addressed.

A mathematical model has been developed using dimensional analysis to predict the surface roughness of the castings based on various parameters of the mould and casting process [36]. Moulds of different thickness were cast with aluminium, copper and brass. Polynomial equations fitted for both experimental and predicted data and had correlation factors close to 1 . The surface roughness was found to increase with a decrease in shell thickness. This was attributed to the erosion of the mould wall due to a decrease in the bonding strength of the part. Additionally, decreasing the wall thickness was reported to have caused an increase in the grain angularity, causing inter-granular voids which allowed for metal penetration. The range of surface roughness values and the prediction error are reported in Table 3.

A study on the effect of shell wall thickness, pouring temperature and density on the hardness of the cast parts for non-ferrous alloys was performed [37]. Using response surface methodology, a quadratic model was developed, establishing the correlation above. The models were validated with Analysis of Variance method with a $99.75 \%$ confidence level. Formulation of such mathematical relations is important for predictions without expensive experimentation. The optimum values are reflected in Table 4 .

To sum up the literature related to the mould and its properties, and point out the gaps in the research before moving to the next section to discuss the design capabilities and accuracy.

- The density and surface roughness of parts produced by the 3D printed moulds is found to be poorer than those produced by traditional sands in Ref. [31], though within acceptable limits for sand casting. However, there have not been any efforts to characterise the exact causes or identify parameters which might

Table 4

Optimum properties for highest Vickers Hardness Number [37].

\begin{tabular}{|c|c|c|c|c|}
\hline Metal/Alloy & Vickers Hardness Number (VHN) & Shell Wall Thickness (mm) & Pouring Temperature $\left({ }^{\circ} \mathrm{C}\right)$ & Density $\left(\mathrm{gm} / \mathrm{cm}^{3}\right)$ \\
\hline $\mathrm{Al}$ & 98 & 5 & 790 & 2.8 \\
\hline $\mathrm{Zn}$ & 56 & 5 & 432 & 7.1 \\
\hline $\mathrm{Pb}$ & 8 & 6 & 330 & 10.2 \\
\hline $\mathrm{Cu}$ & 98 & 6 & 1084 & 8.94 \\
\hline Brass & 98 & 7 & 978 & 8.67 \\
\hline Bronze & 115 & 6 & 1037 & 8.8 \\
\hline
\end{tabular}




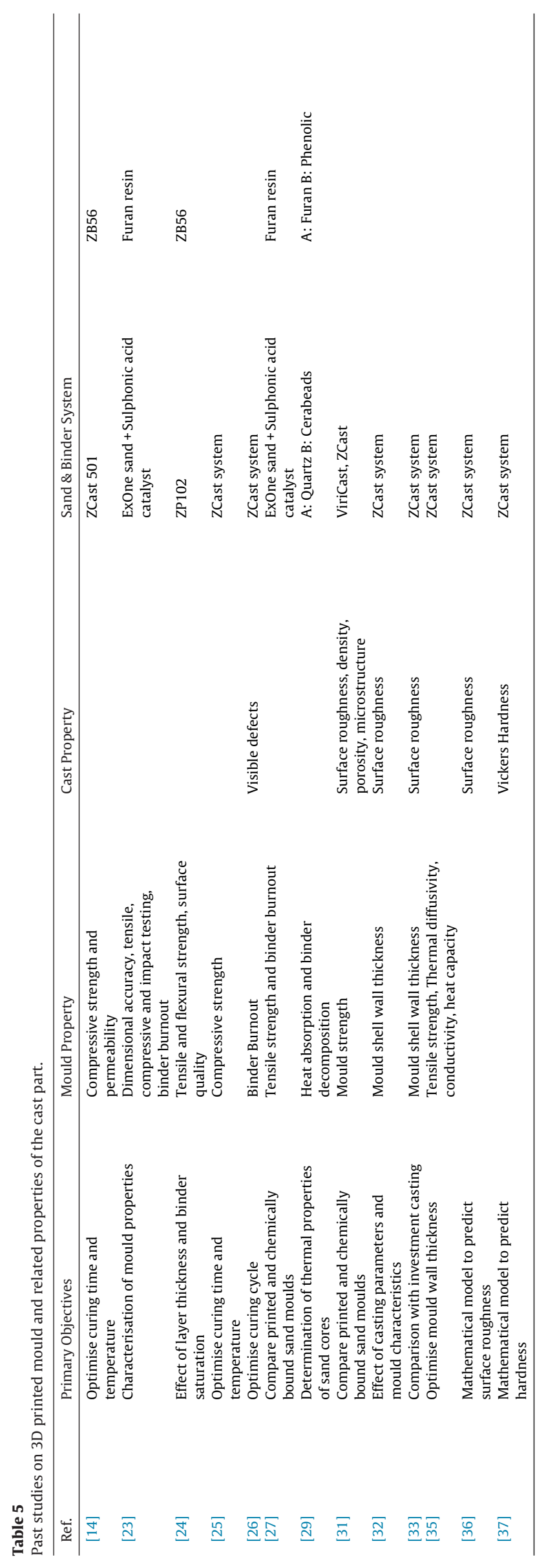

improve the surface quality. The effect of the binder-catalyst concentrations should be explored in the future.

- Only a few studies have been aimed at the properties of 3D printed cores [29]; it is important to characterise the effects of the internal structures in the mould on the cast metal, especially when the design does not allow for proper venting characteristics. This will help identify the process capability for complex internal geometry.

- Most works have focused on the (e.g. ZCast) printers which use powder of plaster-ceramic composition. ${ }^{1}$ Other systems using various sand (e.g. Chromite, Silica, Zircon, or Ceramic Beads)-binder (furan or phenol)-catalyst systems (e.g., ExOne ${ }^{\mathrm{TM}}$, Voxeljet $^{\mathrm{TM}}$ ) may provide better properties, especially due to the lower binder content than the earlier system but not eco-friendly compared to the previous. Work done on new material systems is discussed later.

- Aluminium and its alloys have been the focus of most studies. Work is lacking in the area of other wide range of liquidus point alloys like steel or copper alloys.

- It is worth studying the effect of sand size, binder and activator content and printing speed as these parameters can heavily influence the mould properties.

The studies are summarised, below, Table 5.

\section{Design capability and accuracy}

The 3DP process offers great flexibility in the printing of the mould by integrating the part to be manufactured with the cores, gating and the risering system. It helps evade certain rules of traditional sand casting but imposes other rules due to limits of the process as explained in [38]. The authors evaluate the capability of the VoxelJet ${ }^{\mathrm{TM}}$ VX200 by printing a series of test parts of canonical shapes. A set of guidelines has been established, such as splitting the mould for quick assembly, incorporating positioning pads, mould cost dependence on the part volume (especially height), and drilling vents to help with the release of gases. It was found more suitable to adopt 3D printing for complex geometry and use traditional means for simple shapes. However, these are general guidelines expressed, mainly, in qualitative terms. Establishing clear and detailed standards for the mould design, incorporating weight reduction techniques for any specific part, is important.

Despite the flexibility of the printing that allows for complex mould production, the actual casting is dependent on the properties of the mould and is in some ways restricted by the casting process. The fabrication of light weight metal cellular mesostructures was performed by the combination of 3D printing the part and then casting the component [39]. Here the 3D printed component was used as the core, while the mould was built around it. Initial attempts made using the ZCorp ${ }^{\mathrm{TM}}$ 's Spectrum 510, failed due to the high binder content of the mixture which led to voids and defects due to the resultant off-gassing. The ExOne ${ }^{\mathrm{TM}}$ furan binder system produced better results due to its low and controllable binder content. A356 alloy was cast at $1023 \mathrm{~K}\left(750^{\circ} \mathrm{C}\right)$, with the gating designed to fill the mould as quickly as possible to avoid solidification before complete filling. The part produced was easy to extract from the mould and clean. Thus, homogeneous sandwiched cellular structures were obtained. The authors mention that their work demonstrates the ability of the product to create parts with complex geometry and opens up avenues to cast parts developed using topology optimisation and flow modelling simulations.

$150 / 50$ of Olivine and calcium sulfate hydrate.[14] 
Table 6

Summary of studies on the grades of dimensional tolerance.

\begin{tabular}{|c|c|c|c|}
\hline Ref. & Parameters varied & Metal/Mould & Tolerance grade \\
\hline [41] & Compare investment casting and ZCast process & AlSi10Mg & IT15-IT16 \\
\hline [25] & Optimise curing time and temperature & ZCast Mould & IT15 \\
\hline [8] & Shell Thickness & Aluminum 356 & IT13-IT16 \\
\hline$[44-46]$ & Shell Thickness & Aluminum 333 & IT14-IT15 \\
\hline \multirow[t]{2}{*}{ [47] } & Shell Thickness & Low brass 80 percent alloy & IT11-IT14 \\
\hline & & Solder $20-80$ lead alloy & IT10-IT12 \\
\hline [48] & Shell Thickness & Zinc Alloy & IT12-IT14 \\
\hline
\end{tabular}

The capability of the process also helped researchers develop moulds to study the performance of long, thin cores during the metal casting process [40]. 3DP allowed the researchers to prepare complex harp-shaped moulds, along with appropriate gating systems to test whether the cores would be sufficiently strong to maintain their shape and orientation during pouring and also to observe whether the gases produced could be effectively vented from the internal passages. The tubes were of wall thickness $1.54 \mathrm{~mm}$, internal diameters of $6.35 \mathrm{~mm}-22.22 \mathrm{~mm}$ and lengths $50.8 \mathrm{~mm}-304.8 \mathrm{~mm}$. A harp-shaped core for each diameter was fabricated with internal vents for the casting. The authors point out that such a complex shape with small dimensions would be tough to fabricate by traditional means. Six tubes were created for each diameter resulting in a total of 72 castings. Cores with a diameter equal to or more than $9.5 \mathrm{~mm}(0.375 \mathrm{in}$.) were robust enough to prevent significant deformation during the metal-casting.

To evaluate the application limits and feasibility of Rapid Casting processes on the basis of time, cost and dimensional tolerances, a study was performed by casting technological prototypes with starch-based investment casting and the ZCast selective jetting process [41]. AISI 304 Steel was cast via the investment casting technique, by 3D printing the pattern, followed by shell formation and then pattern evacuation at $1173 \mathrm{~K}\left(900^{\circ} \mathrm{C}\right)$. For the ZCast process, simulations were performed using SOLIDCast ${ }^{\circledR}$ to define the gating systems. The mould was then printed, cleaned, painted and assembled followed by the pouring of the aluminium alloy. The dimensions were then measured on a coordinate measuring machine. These would include the errors introduced during STL file generation, printing of moulds, mould treatment and assembly and solidification shrinkage. The tolerances evaluated as per the guidelines of International Organization for Standardisation using the International Tolerance (IT) grades [42]. The obtained tolerance grades were in the range of IT 15-16.

In another study, ZCast rapid casting process was classified in the IT 15 grade [25]. It was found that this grade is independent of the applied heat treatment. Another study [8] confirms the above results by comparing the aluminium castings produced by investment casting and the ZCast process. The moulds were printed as shells with sand backing during the casting for the ZCast process. For the investment casting, expendable patterns were manufactured, and the traditional process of shell formation and pattern evaluation was applied. The dimensions were measured. The calculated tolerance was in the range of IT 13-16 which is consistent with casting operation values according to the ISO Standard UNI EN 20286-I (1995). These studies indicated that the binder jetting process for rapid casting could produce parts in short times, avoiding tooling cost [43] with dimensional tolerances in the range of traditional casting processes.

The authors in [44-46] attempt to optimise the wall thickness to provide best accuracy and hardness of the casting. They found that with a thickness of $5 \mathrm{~mm}$, the hardness improved by $3.8 \%$ while reducing cost and production time by $54.6 \%$ and $55.4 \%$ respectively. The tolerance grades for the cast parts were between IT14-IT15, consistent with casting requirements. Others [47] performed a similar study for the casting of lead and brass alloys using
3D printing, claiming that to produce sound castings with minimum wall thickness, pouring temperature, weight and density are critical parameters. The IT grades were reported between IT10-IT12 for lead alloys and IT11-IT14 for brass alloys. Similarly, in Ref. [48], the tolerance grades for Zinc alloys were found to lie between IT12IT14 and the optimum thickness was found to be $3 \mathrm{~mm}$. These studies on tolerance grades are summarised, Table 6.

From an industrial standpoint, the cost and the process capability are important parameters which determine market penetration. The cost-effectiveness of the 3DP process for sand moulding depends on the part complexity and the volume of production [49]. It believed that the cost per part for 3DP remains constant irrespective of the complexity, compared to the exponentially rising cost of traditional manufacturing. The study compares two cases by increasing the complexity of the mould by successively adding cores. The complexity is estimated by an index, "Complexity Factor", which accounts for the various geometrical attributes of the mould and core assembly [50]. The costs of manufacturing were estimated and analysed as a function of the complexity factor for both methods and breakeven points determined. The study found that not only is the 3DP process cost effective for complex geometries (even up to 1000 units) but also for low volumes of production (45 units with minimal complexity). However, the costs get amortised for high volumes of production in conventional manufacturing, making it more affordable than 3DP. The cost of 3DP is highly sensitive to the cost of materials and operation, which greatly affects the breakeven point. Thus, the increase in the demand for the 3D printed powders can lead to a consequent drop in price, improving the attractiveness of rapid casting to the industry. Using a similar benchmarking process, authors in [51] developed process chains to minimise costs and lead times. These are optimised based on influencing factors such as production scale, part size and complexity, and cast materials. The part's complexity is evaluated by examining it for internal and external undercuts and the surface at the splitting line and finally assigning a complexity code based on this information. Finally, based on these factors and the production priority i.e. shortest time or lowest cost, the method helps one choose between direct metal casting, loose pattern method, production intent casting or fibreglass tooling.

Another study in the automotive industry was able to demonstrate cost savings of $50 \%$ and reduction in lead times from 12 weeks to 3 weeks by using rapid casting technologies (RCT) [52]. RCT was used to create tooling for manufacturing automotive seats. A set of 120 seats were produced with no loss in quality with an increase in flexibility of the process. The process allowed for quick modifications in design, no design restrictions on moulds and near net shape castings requiring minimal post-processing. The authors also highlight how each mould is designed and tested stringently to perform right at the first time as it must be shipped to the foundries and takes significantly longer to print than traditionally mould. Improper foundry conditions can cause moisture absorption in moulds, which can cause significant off-gassing. These can be combatted through proper mould drying and the introduction of gas vents. There also arises the situation of a breakeven of traditional vs 


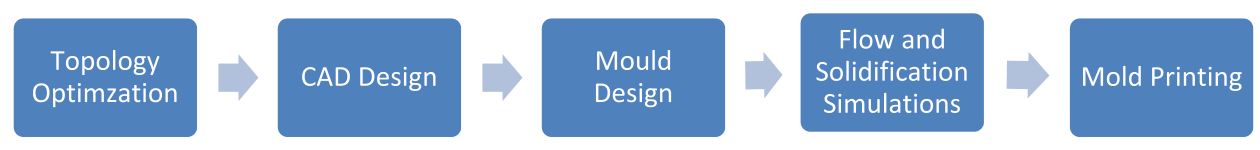

Fig. 5. Combining topology optimization with rapid casting process.

printed moulds based on cost, time and complexity that a foundry must consider before they adopt printed mould technology.

Industries have begun to exploit the use of 3DP in conjunction with topology optimisation. A cast part in the woodworking industry in Finland was redesigned for optimum material distribution [53]. The risers and gating system were added and then casting simulations were performed. After modifications to the design to obtain satisfactory results, the part was cast to obtain weight savings up to $38 \%$. The authors were even able to incorporate stainless steel tubes for internal air channels in the mould before casting. The process flow is shown in Fig. 5.

The related open literatures are summed up, and the identified gaps in the research for further study are pointed out below.

- It is important to establish better guidelines, procedures, and standards for mould design to facilitate the removal of loose sand particles and produce robust 3D printed sand moulds on assembly. Due to the limitation of loose sand parts, closed cavities cannot be produced, additionally all cavities must be accessible to remove particles via vacuum and allow cleaning of the inner surface.

- Study the capability of the process to produce parts with an unconventional geometry such as those produced by topology optimisation. The process can allow designers to work without manufacturing restrictions allowing them to focus on designing for the best performance.

- Apart from producing parts with complex geometry, the method also allows for the integration of novel filling and optimised risering systems into the mould design, which are not possible by conventional mould making process. Various casting simulation packages can aid this process by flow modelling simulations.

- Foundries must adopt a different mindset while using printed moulds, by performing breakeven analysis and adapting a full printed vs a hybrid approach. Large simple mould sections can be made using the traditional approach while more complex parts can be printed.

Now, let's focus on the powders and binder systems used for the production of 3D printed moulds and to discuss the challenges in manufacturing such parts.

\section{Material systems and the issues in the $3 D$ printing technology}

As previously mentioned, the cost of 3DP highly depends on the expense of the materials used and hence an effort to develop the materials utilised for the process may significantly enhance the profitability of the process and could enable its widespread use. Ref. [54], presented a review of the various steps required for the development of new material systems about 3DP. These steps relate to the selection of powder and binder, the formulation of the printing liquid, the interaction of the deposited powder and the binder and finally the post processing of the green part. Not only does the work detail the properties required by the powder and binder for effective printing but also explain the various additives which can help achieve these properties. While this study deals, primarily, with ceramic and metal based 3DP, the insights from the review can be applicable in the 3DP of sand moulds.
Sand used for printing requires it to be spread with a constant density and height in machines envelopes of areas upto $2 \mathrm{~m}^{2}$. As such the sand requires good flowability, ability to be compacted easily and stability at rest. It also requires good permeability to be used for casting purposes. Thus, development of alternate sand-binder systems requires a very careful and methodological approach. A detailed study has been conducted to evaluate the suitability of regionally available resins, aggregates and additives for printing with an aim of improving the economy, applications and quality of rapid casting using furan [43]. 11 aggregates were evaluated for their mechanical, physical and chemical properties. The study determined the acceptability of printed moulds on the mechanical strength and handleability, and showed that their system was able to print a wide variety of materials with good casting results. In the academic front, such research is required to break the material restrictions imposed by manufacturers and study the properties of various materials to determine their suitability for the replacement of manufacturer supplied material.

A sand-gypsum substitute for the ZCast 501 or Zb56 powder was developed and used to successfully cast aluminium, magnesium, and iron [55]. X-ray phase analysis were performed to determine the constituents of the powder. The effect of the concentration of various modifiers such as $\mathrm{Fe}_{2}(\mathrm{SO} 4)_{3}$ as a hardening accelerator and dolomite meal as a moisture absorber were also studied. They also obtained a composition for the substitute of the $\mathrm{Zb} 56$ providing satisfactory results. Another substitute for sand binder systems (SBS) was developed by Ref. [20]. in the form of inorganic binders, wetted by water and then finally cured. Unlike the furanic binder-catalyst systems, in which the catalyst already wetted the sand, and then binder was sprayed on the sand bed, the proposed system uses a mix of quartz sand and dry sodium silicate powder which is wetted by water dispensed by the printer head. This forms resin bridges which are strengthened by dehydration using an infrared (IR) torch. The process parameters studied were concentration ratio and heat input. The effects of these were assessed through quality features such as the strength of specimens and fluid migration (movement of the binder into non-printed areas). Thermal activation using the IR emitter reduced the fluid migration to $24 \%$ from $34 \%$. The study found that increase in fluid migration leads to higher mechanical strength but poorer dimensional accuracy due to excess sand adhesion. The experiments were conducted on a small number of process conditions and limited properties were analysed. However, the work here is interesting as fluid migration is a property which is directly shown to affect the dimensional accuracy of the part obtained and can be used as an important measure to evaluate new sand-binder systems. The authors plan to conduct more investigations by varying more process parameters, analysing more properties and determining Young's modulus and Poisson's ratio.

Another study demonstrated a novel light-based curing system for 3D printed sand moulds [56]. The authors have proposed a hybrid rapid casting approach in which the $8 \mathrm{~mm}$ thick layers of resin-coated sand were bonded by using a light source, by heat application to cause curing, followed by precision machining to obtain the desired shapes. Tests were conducted to determine the physical, chemical and mechanical properties including permeability and castability of the produced mould specimens. Further studies are required to evaluate the optimum layer thickness, machining parameters and properties of produced castings by this method. 
Researchers also worked on modifying the existing furan binder mix to study its curing mechanism and change in thermal strength [57]. The effects of modifiers such as sorbitol, polyester pylols, phenol, and acetone were studied using thermal gravity analysis. The authors use Differential Thermal Analysis to conclude that dehydration polycondensation and ring opening reactions are the dominating curing reactions. These result in a three-dimensional structure which contributes to the resin strength. The effect of the modifiers, except polyester polyol, is minimal on the thermal strength. This strength improved at temperatures higher than $823 \mathrm{~K}$ $\left(550^{\circ} \mathrm{C}\right)$, and derived a conclusion that the modified resin is a suitable candidate for core moulding.

Apart from the research in new materials for additively manufactured moulds, there have been innovations in the powder delivery and printing machines. Voxeljet ${ }^{\mathrm{TM}}$ revealed the world's first continuous 3D printer at EuroMould 2012 [58,59]. The printer uses a horizontal belt conveyor which is inclined at an angle less than the angle of repose of the sand. After every layer, the conveyor moves the entire fill by one layer thickness towards the unloading area. The main advantage of the process is the simultaneous part printing and unloading. Also, the unused sand is directly returned to the build zone post unpacking. In addition to the virtually unlimited length of the mould produced, the process also promises faster printing as positioning on an incline is faster. This process shows great promise for mass production and may lead to better acceptance of the process across the market. A study on the dimensional tolerance of casting produced using these moulds and design techniques to produce long and narrow channels containing parts of various casting alloys is essential.

To sum up the literature and the gaps in the research for further study,

- Considering environmental, health and safety issues, the toxicity of the furan resin must be addressed. New material systems must be developed for the rapid sand casting process.

- It is important to delve into the mechanics of flow of binder through the granular sand media to understand the bonding characteristics of the material systems.

- As more new binder-powder systems for 3D printed moulds develop, it will become necessary to set standards for the proper evaluation and testing of these moulds and subsequently the parts produced by such moulds.

\section{Conclusions and future perspectives}

Innovative hybrid solutions have now come to the forefront with rapid developments in the additive manufacturing industry. The suitability of 3DP to rapid sand casting applications has led to the adoption of the process by large-scale manufacturers but it is still a long way to go before its presence is ubiquitous in smaller scale foundries. Nevertheless, it is still being utilised by these foundries through build-to-order by large enterprises, for prototyping a new design. Its relatively high initial investment, running and material costs, and limitations on production volume have hindered its rapid penetration into today's markets. While it offers a significant advantage by way of mould complexity, the printing is much slower than traditional moulding processes for large scale production. Unless a field of 3D printers is employed, the slow speed makes it unsuitable for large scale daily production. Additionally, there is, for now, a limit on the size of the job-box, which requires one to produce moulds in multiple parts which must then be assembled together, and hence production of large castings become difficult. While the process is not poised to completely replace the traditional moulding, by furthering research in this direction, the advantages will soon be able to outweigh the limitations, enabling this tech- nology to be universally accepted and utilised as a complement to traditional moulding practices.

The cost of the currently available materials for sand 3DP can be reduced with the demand in the near future as the research focus in the field and the number of newly released advanced 3D printers are in the increasing trend. This demand is currently limited by the high initial investment and running cost of the machines. Hence, an improvement in materials for the rapid casting industry is vital important for better acceptance of the process. Currently, material supply is controlled by machine manufacturers and thus it is difficult for academics to experiment with different materials and to establish their properties. Research focus on developing new materials compatible with commercial systems will aid in development of the process.

3D sand mould printing technology provides an excellent solution to the industry need, with minimal change to the current casting industry; only the sand mould assembly is produced, and the casting process will be the same based on the millenniums of the knowledge base. It eliminates many of the design rules for sand casting and still be the better option for rapid prototyping and even comparable better technology than the direct metal printing technology when considering a large scale castable part design with a variety of alloy material choice and optimised part design. It still lacks the design knowledge to successfully and economically produce a very complex part with narrow and long channels in the design, whereas the direct metal printing can easily be utilised at the expense of time and money.

\section{Acknowledgements}

1st author greatly acknowledges the financial support for this work, and to visit MSMP laboratory in France, to carry out other 3D printing related experimental work, by the Campus France through the Charpak Scholarship scheme.

\section{References}

[1] F42.91. Standard Terminology for Additive Manufacturing - General Principles - Terminology. ASTM Int; 2015.

[2] Wong KV, Hernandez A. A review of additive manufacturing. ISRN Mech Eng 2012;2012:1-10, http://dx.doi.org/10.5402/2012/208760.

[3] Bak D. Rapid prototyping or rapid production? 3D printing processes move industry towards the latter. Assem Autom 2003;23:340-5, http://dx.doi.org/10.1108/01445150310501190.

[4] Wohlers T. Wohlers report 2003: Additive manufacturing and 3D printing state of the industry: Annual worldwide progress report; 2003.

[5] Chhabra M, Singh R. Rapid casting solutions: a review. Rapid Prototyp J 2011;17:328-50, http://dx.doi.org/10.1108/13552541111156469.

[6] Scopus Analyze search results 2017: Documents Query [170613-005374] https://www.scopus.com/search/form.uri.

[7] Dimitrov D, Schreve K, De Beer N. Advances in three dimensional printing - state of the art and future perspectives. Rapid Prototyp J 2006;12:136-47, http://dx.doi.org/10.1108/13552540610670717.

[8] Gill SS, Kaplas M. Comparative study of 3D printing technologies for rapid casting of aluminium alloy. Mater Manuf Process 2009;24:1405-11, http://dx.doi.org/10.1080/10426910902997571.

[9] Pham D, Gault R. A comparison of rapid prototyping technologies. Int J Mach Tools Manuf 1998;38:1257-87, http://dx.doi.org/10.1016/S0890-6955(97)00137-5.

[10] Sachs E, Cima M, Three-Dimensional Printing: Rapid Tooling Cornie J. Prototypes directly from a CAD model. CIRP Ann Manuf Technol 1990;39:201-4.

[11] Sachs EM, Haggerty JS, Cima MJ, Williams PA. Three-dimensional printingtechniques; 1993.

[12] Low Z-XX, Chua YT, Ray BM, Mattia D, Metcalfe IS, Patterson DA. Perspective on $3 \mathrm{D}$ printing of separation membranes and comparison to related unconventional fabrication techniques. J Memb Sci 2017;523:596-613, http://dx.doi.org/10.1016/j.memsci.2016.10.006.

[13] ExOne. A Case Study in Optimizing Casting Design Using 3 D Printing; 2017 http://www.afsinc.org/multimedia/MCTVDetail.cfm?ItemNumber=19145.

[14] Mckenna N, Singamneni S, Diegel O, Singh D, Neitzert T, George JS, et al. Direct Metal casting through 3D printing: a critical analysis of the mould characteristics. 9th Glob Congr Manuf Manag 2008:12-4.

[15] ZPrinter ${ }^{\circledast}$ Consumables Catalogue (2013). 
[16] ExOne. ExOne offers a variety of manufacturing quality materials that stand up to industrial use and easy integration into existing processes; 2017 (accessed June 13, 2017) http://www.exone.com/Resources/Materials.

[17] Sivarupan T, ElMansori M, Coniglio N. 3D printing process parameters and properties of additively manufactured sand mold for rapid casting: strength and permeability. Addit Manuf 2017 (accepted).

[18] ExOne. Production Printers n.d. http://www.exone.com/Systems/ProductionPrinters (accessed February 9, 2017).

[19] Voxeljet Sand casting molds - Rapid and economical n.d. http://www.voxeljet. de/en/materials/sand/ (accessed February 2, 2017).

[20] Ramakrishnan R, Griebel B, Volk W, Günther D, Günther J, G\&uuml;nther D, et al. 3D printing of inorganic sand moulds for casting applications. Adv Mater Res 2014;1018:441-9, http://dx.doi.org/10.4028/www.scientific.net/AMR.1018.441.

[21] Bakhiya N, Appel KE. Toxicity and carcinogenicity of furan in human diet. Arch Toxicol 2010;84:563-78, http://dx.doi.org/10.1007/s00204-010-0531-y.

[22] ExOne. 3D Printing Binders; 2017 (accessed March 13, 2017) http://www. exone.com/Resources/Binders.

[23] Hackney PM, Wooldridge R. Characterisation of direct 3D sand printing process for the production of sand cast mould tools. Rapid Prototyp J 2017;23:7-15, http://dx.doi.org/10.1108/RPJ-08-2014-0101.

[24] Vaezi M, Chua CK. Effects of layer thickness and binder saturation level parameters on 3D printing process. Int J Adv Manuf Technol 2011;53:275-84, http://dx.doi.org/10.1007/s00170-010-2821-1.

[25] Bassoli E. Atzeni E. Direct metal rapid casting: mechanical optimization and tolerance calculation. Rapid Prototyp J 2009;15:238-43, http://dx.doi.org/10.1108/13552540910979758.

[26] Snelling DA, Kay R, Druschitz A, Williams CB. Mitigating gas defects in castings produced from 3D printed molds. 117th Met Congr 2012:3-9.

[27] Snelling D, Williams CB, Druschitz AP. A comparison of binder burnout and mechanical characteristics of printed and chemically bonded sand molds. SFF Symp 2014:197-209.

[28] Bednarz M. Cold Hardening Phenol: The new all-rounder among binder systems. ExOne; 2017 (accessed March 30, 2017) http://www.exone.com/ About-ExOne/News/View/ArticleId/67/Cold-hardening-phenol-The-new-allrounder-among-binder-systems.

[29] Svidró JT, Diószegi A. Heat absorption capacity and binder degradation characteristics of 3D printed cores investigated by inverse Fourier thermal analysis Heat Absorption Capacity and Binder Degradation Characteristics of 3D Printed Cores Investigated by Inverse Fourier Therma; 2015.

[30] Stevenson D. 3D Sand Printing -Cores \& Moulds for the Foundry Industry Agenda; 2015.

[31] Snelling D, Blount H, Forman C, Ramsburg K, Wentzel A, Williams C, et al. The effects of 3D pritned molds on metal castings. Solid Free Fabr Symp 2013:827-45

[32] Chhabra M, Singh R. Obtaining desired surface roughness of castings produced using ZCast direct metal casting process through Taguchi\&apos;s experimental approach. Rapid Prototyp J 2012;18:458-71, http://dx.doi.org/10.1108/13552541211272009.

[33] Gill SS, Kaplas M. Efficacy of powder-based three-dimensional printing (3DP) technologies for rapid casting of light alloys. Int J Adv Manuf Technol 2011:52:53-64.

[34] Phanikumar G, Chattopadhyay K. Solidification microstructure development. Sadhana 2001;26:25-34, http://dx.doi.org/10.1007/BF02728477.

[35] Drokina VV, Belov VD, Chekhonin SN. Obtaining casts of aluminum alloys by foundry in loose molds fabricated on installations of three-dimensional printing. Russ J Non-Ferrous Met 2011;52:24-8, http://dx.doi.org/10.3103/S1067821211010081.

[36] Chhabra M, Singh R. Mathematical modeling of surface roughness of castings produced using ZCast direct metal casting. J Inst Eng Ser C 2015;96:145-55, http://dx.doi.org/10.1007/s40032-014-0139-8.

[37] Kumar R, Singh I, Singh R. Modeling and analysis for hardness and structure of nonferrous alloy castings produced using zcast metal casting process through response surface methodology. Int J Adv Res Innov 2015;3:232-41.
[38] Bonnefoy H. Mould design method with sand 3D printing: 2014.

[39] Snelling D, Li Q, Meisel N, Williams CB, Batra RC, Druschitz AP. Lightweight metal cellular structures fabricated via 3D printing of sand cast molds. Adv Eng Mater 2015;17:923-32, http://dx.doi.org/10.1002/adem.201400524.

[40] Mueller T, Andre L. Printing long, thin cores for aluminum sand castings. Met Cast Des Purch 2015;17(6):27-32.

[41] Bassoli E, Gatto A, Iuliano L, Violante MG. 3D printing technique applied to rapid casting. Rapid Prototyp J 2007;13:148-55, http://dx.doi.org/10.1108/13552540710750898.

[42] BS EN ISO 286-1:2010, Geometrical product specifications (GPS) - ISO code system for tolerances on linear sizes - Part 1: Basis of tolerances, deviations and fits; 2010.

[43] Thiel J, Ravi S, Bryant N. Advancements in materials for threedimensional printing of molds and cores. Int J Met 2017;1:1, http://dx.doi.org/10.1007/s40962-016-0082-y.

[44] Singh R, Verma M. Investigations for reducing wall thickness of aluminium shel casting using three dimensional printing. J Achiev Mater 2008;31:565-9.

[45] Singh R. Process capability study of a rapid casting solution $f$ or aluminium alloys using three - dimensional printing. Int J Automot Mech Eng 2011;4:397-404.

[46] Singh R. Three dimensional printing for casting applications: a state of art review and future perspectives. Adv Mater Res 2009;83-86:342-9, http://dx.doi.org/10.4028/www.scientific.net/AMR.83-86.342.

[47] Singh R, Singh JP. Comparison of rapid casting solutions for lead and brass alloys using three-dimensional printing. Proc Inst Mech Eng Part C J Mech Eng Sci 2009;223:2117-23.

[48] Singh R. Effect of moulding sand on statistically controlled hybrid rapid casting solution for zinc alloys. J Mech Sci Technol 2010;24:1689-95, http://dx.doi.org/10.1007/s12206-010-0523-0.

[49] Almaghariz ESES, Conner BPBP, Lenner L, Gullapalli R, Manogharan GPGP, Lamoncha B, et al. Quantifying the role of part design complexity in using 3d sand printing for molds and cores. Int J Met 2016;10:240-52, http://dx.doi.org/10.1007/s40962-016-0027-5.

[50] Joshi D, Ravi B. Quantifying the shape complexity of cast parts. Comput Aided Des Appl 2010;7:685-700.

[51] Dimitrov D, van Wijck W, de Beer N, Dietrich J. Development, evaluation, and selection of rapid tooling process chains for sand casting of functional prototypes. Proc Inst Mech Eng Part B: J Eng Manuf 2007;221:1441-50, http://dx.doi.org/10.1243/09544054JEM728.

[52] Hackney PM, Wooldridge R. Additive manufacturing for automotive mass production tools. Rapid Des Prototyp Manuf Conf 2015

[53] Komi E, Kokkonen P, Virta J, Puukko P, Sini M-K. Simulation, optimisation and design of a 3D printed sand mould for a cast metal component. In: Paasi J, editor Towar. a new era Manuf. Julkaisija; 2017. p. 72-80.

[54] Utela B, Storti D, Anderson R, Ganter M. A review of process development steps for new material systems in three dimensional printing (3DP). J Manuf Process 2008;10:96-104, http://dx.doi.org/10.1016/j.jmapro.2009.03.002.

[55] Koltygin AV, Bazhenov VE. Development of a substitute for z cast molding sand used on installations of 3D printing for obtaining aluminum, magnesium, and iron casting. Russ J Non-Ferrous Met 2012;53:38-41, http://dx.doi.org/10.3103/S1067821212010129.

[56] H B, S, R, M J. Evaluation of a 3D Light Cured Sand for Rapid Casting Technology Evaluation of a 3D Light Cured Sand for Rapid Casting Technology. AFS Trans 14-062 (2015) 1-9.

[57] Renhe H, Hongmei G, Yaoji T, Qingyun L. Curing mechanism of furan resin modified with different agents and their thermal strength. China Foundry 2011:8:161-5

[58] VXC800. World's first 3D continuous printer. 3ders; 2012.

[59] Continuous 3D Printer Foundry Manag Technol; 2012. 